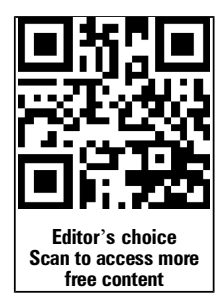

free content

\title{
Long-term prognosis of complete percutaneous coronary revascularisation in patients with diabetes with multivessel disease
}

\author{
Manuel F Jiménez-Navarro, ${ }^{1}$ Francisco López-Jiménez, ${ }^{2}$ Gregory Barsness, ${ }^{2}$ \\ Ryan J Lennon, ${ }^{2}$ Gurpreet S Sandhu, ${ }^{2}$ Abhiram Prasad ${ }^{3}$
}

${ }^{1}$ UGC Corazón, Instituto de Biomedicina de Málaga (IBIMA), Hospital Universitario Virgen de la Victoria, Universidad de Málaga, RIC (Red de Investigación Cardiovascular), Málaga, Spain ${ }^{2}$ The Division of Cardiovascular Diseases and Department of Internal Medicine and Section of Biostatistics, Mayo Clinic, Rochester, Minnesota, USA ${ }^{3}$ Institute of Cardiovascular and Cell Sciences, St George's, University of London, London, UK

\section{Correspondence to} Dr Abhiram Prasad, Institute of Cardiovascular and Cell Sciences, St George's, University of London, Cranmer Terrace, London SW17 ORE, UK; aprasad@sgul.ac.uk

Received 16 November 2014 Revised 7 March 2015 Accepted 18 March 2015 Published Online First 16 April 2015

\section{SLinked}

http://dx.doi.org/10.1136/ heartjnl-2015-307843

\section{CrossMark}

To cite: Jiménez-
Navarro MF, López-
Jiménez F, Barsness G, et al.
Heart 2015;101:
1233-1239.

To cite: Jiménez-

Jiménez $F$, Barsness $G$, et al. 1233-1239.

\section{ABSTRACT}

Objective There is a paucity of data on the impact of complete revascularisation (CR) following percutaneous coronary intervention ( $\mathrm{PCI}$ ) among patients with diabetes with multivessel coronary disease. In this study, we assess the impact of $C R$, using a relatively simple anatomical definition, on long-term outcomes (median follow-up 7.9 years) in patients with diabetes, and compare with patients without diabetes.

Methods 5350 patients with multivessel disease (coronary stenoses $\geq 70 \%$ in $\geq 2$ major epicardial arteries) who underwent PCl between January 1997 and June 2011 were included. Patients were divided into 4 groups according to diabetes and CR status (absence of residual coronary stenosis in major, predominantly proximal, epicardial segments according to Coronary Artery Surgery Study (CASS) classification).

Results Patients with diabetes and patients with incomplete revascularisation (IR) had more adverse clinical and angiographic characteristics. IR was frequent in patients with diabetes, and was marginally more common than in patients without diabetes (47\% vs $44 \%, p<0.001)$. Patients with diabetes and patients without diabetes had higher mortality rates after IR than after CR (HR 1.56 (95\% Cl (1.39 to 1.85), $p<0.001$ for patients with diabetes and $1.70(95 \% \mathrm{Cl}(1.50$ to 1.92$)$, $\mathrm{p}<0.001)$ in patients without diabetes). However, the absolute risk was higher for patients with diabetes (5-year mortality: IR 35.8\%, CR 21.2\%) than in patients without diabetes (5-year mortality: IR $22.2 \%$, CR $14.1 \%)$. In a multivariable model, IR and diabetes mellitus were independent predictors of total mortality. This effect was present in the bare metal stent and drugeluting stent eras and in patients with stable disease and acute coronary syndromes.

Conclusions CR is associated with lower long-term mortality in patients with diabetes and patients without diabetes. However the difference was significantly greater in patients with diabetes compared with patients without diabetes.

\section{INTRODUCTION}

The prevalence of diabetes mellitus (DM) and associated morbidity and mortality due to cardiovascular disease is on the rise in the USA and around the world. ${ }^{1}$ This fact represents a major threat to the recent progress made in the prevention and treatment of coronary artery disease. Therefore, improved understanding of the mechanisms implicated in development and prognosis of coronary artery disease in patients with diabetes is essential. Currently, there is a paucity of data on the impact of incomplete revascularisation (IR) following percutaneous coronary intervention (PCI) among patients with diabetes with multivessel disease. ${ }^{2}$

Moreover, the data on IR in general are controversial and inconclusive due to the use of inconsistent definitions, ${ }^{3}$ variable thresholds for defining significant obstructive atherosclerosis, ${ }^{4}$ combination of percutaneous or surgical revascularisation, ${ }^{5}$ evolution in PCI techniques over time, ${ }^{6}$ and analyses being restricted to selective patient populations. ${ }^{4} 8$ The published studies are post hoc analyses from clinical trial ${ }^{467}$ or administrative databases ${ }^{89}$ and do not provide long-term outcomes among an allcomers diabetic population undergoing PCI. We hypothesised that IR is associated with adverse outcomes following PCI in patients with diabetes. The aim of this study was to evaluate the frequency and impact of IR on long-term mortality and revascularisation from a large consecutive series of patients with diabetes with multivessel disease undergoing PCI for stable angina and acute coronary syndromes (ACS) using a simple, intuitive definition of IR, and comparing their outcomes with patients without diabetes.

\section{METHODS}

All patients undergoing PCI at the Mayo Clinic in Rochester, Minnesota, are prospectively enrolled in a registry which includes demographic, clinical, angiographic and procedural data. Follow-up of all patients is standardised with recording of immediate postprocedural and inhospital events and phone surveys using a standardised questionnaire at 6 months, 1 year and then annually after the procedure by trained data technicians. Routinely, $10 \%$ of all records are randomly audited by the supervisor for data integrity. All adverse events are confirmed by reviewing the medical records of the patients followed up at our institution and by contacting the patients' physicians and reviewing the hospital records of patients treated elsewhere.

\section{Study population}

The study included patients from January 1997 to June 2011. Subjects with multivessel disease, defined as coronary stenoses $\geq 70 \%$ in two or more of the three major epicardial arteries and their branches were included in this analysis. Lesions of interest for revascularisation had to involve the 
following segment Coronary Artery Surgery Study (CASS) classification ${ }^{10}$ (segments 1,2,3 for right coronary; segment 11 for left main; segments 12 and 13 for left anterior descending; and finally segment 18 for circumflex (and 19 if left dominant/ balanced are present)). Exclusion criteria were cardiogenic shock prior to PCI, prior coronary artery bypass graft (CABG) surgery, unsuccessful PCI in any lesion, and refusal of research authorisation. The earliest complete qualifying PCI per patient was considered the index event. The primary group of interest was those with DM but data on patients without diabetes is also provided for comparison.

To assess the impact of PCI technique, patients were divided into two groups according to the date of their intervention: (1) the bare-metal stent (BMS) era (January 1997 through March 2003) included patients from a time period during which routine stenting with such stents was the preferred strategy in conjunction with dual oral antiplatelet therapy; and (2) the drug-eluting stent (DES) era (April 2003 through June 2011) consisted of patients whose PCI reflects contemporary practice.

In accordance with a State of Minnesota statute, patients who did not grant authorisation for medical records research were also excluded from the analysis (205 patients between 1 January 1990 and 30 June 2011).

\section{Definitions}

DM was defined as a documented history of diabetes treated with medication or diet. Complete revascularisation (CR) was defined as successful PCI to all significant lesions in the segments of interest during the index hospitalisation. Conversely, IR was defined if there was successful PCI to one more lesion but there was at least one significant lesion in the segments of interest that was not treated. Procedural success was defined as a reduction of residual luminal diameter stenosis to no more than $20 \%$ without inhospital death, Q-wave myocardial infarction (MI) or need for emergency CABG. Acute coronary syndrome was defined as either (1) MI within the previous 7 days or (2) unstable angina requiring non-elective PCI.

Primary end point of interest was all-cause mortality following discharge. Secondary end point was any target lesion revascularisation.

\section{Statistical analysis}

Continuous data are summarised as mean (SD) unless otherwise stated. Categorical data are summarised as frequency (group percentage). Group comparisons were made between patients with and without diabetes and between completely revascularised and incompletely revascularised patients within diabetes status. One-way analysis of variance and Pearson's $\chi^{2}$ tests are used for continuous and categorical data, respectively. Ordinal variables are tested using the Kruskal-Wallis test. Kaplan-Meier methods are used to estimate follow-up event rates, with follow-up beginning at time of discharge (unsuccessful PCIs and patients who died in hospital were excluded); group tests were conducted with the log-rank test. Survival plots demonstrate the absolute risk reduction over time. Multiple Cox regression models for mortality were constructed with risk-adjustment through the Mayo Clinic Risk Score for long-term mortality. ${ }^{11}$ Models for repeat revascularisation also adjusted for age, gender, current smoker, history of MI, history of peripheral vascular disease, cerebrovascular accident/transient ischaemic attack, calcium in stenosis, device size and use of DES. Also included in the models were indicator variables for diabetes, CR and the interaction between those two factors. HRs from the models reflect the relative risk of patients with diabetes versus those without and for IR versus CR. Interaction effects were retained regardless of the significance of the interaction to demonstrate effect sizes within subgroups of DM and CR. The proportional hazards assumption was assessed by means of plotting scaled Schoenfeld residuals over time and overlaying a scatter plot smoother with $95 \%$ CIs. There was no evidence of a violation of the assumptions.

\section{RESULTS}

Five thousand three hundred and fifty patients with multivessel disease undergoing PCI met the inclusion criteria for this study. Of these, 1425 (26.6\%) had, and 3925 (73.4\%) did not have DM. IR was present in 2377 (44.4\%) patients, and it was marginally more frequent in patients with diabetes $668 / 1425$ (46.9\%) compared with patients without diabetes 1709/3925 $(43.5 \%), \mathrm{p}<0.001$.

\section{Baseline clinical characteristics}

Main differences between groups are described; Comparison patients with diabetes versus patients without diabetes; patients with diabetes with IR versus CR (table 1).

\section{Angiographic and procedural characteristics}

Compared with patients without diabetes, patients with DM presented unfavourable characteristics and use of DES was higher (table 2).

Patients with diabetes with IR, compared with those with CR, had more severe disease. Patients with IR also received fewer stents and were less likely to have DES.

\section{Long-term outcomes}

The median duration of follow-up was 7.9 (IQR 4.2, 10.8) years. Fifty-nine per cent of patients had follow-up available within 1 year of freezing the data for analysis, and $79 \%$ had follow-up available in the prior 2 years. Patients with DM had a higher mortality, and those with IR had significantly greater mortality compared with those with CR (figure $1, \mathrm{p}<0.001$ ). In subgroup analyses among patients with diabetes, the differential outcome between IR and CR was present during the BMS and DES eras (figure 2); and when PCI was performed for stable disease versus ACS (figure 3).

In univariate analysis, patients with diabetes and patients without diabetes with IR had higher mortality rates compared with those with CR (HR 1.56 (95\% CI (1.39 to 1.85), $\mathrm{p}<0.001)$, and was 1.70 (95\% CI (1.50 to 1.92$), \mathrm{p}<0.001)$, respectively. Though the relative risk was similar, the absolute risk was higher for patients with diabetes (5-year mortality: IR $35.8 \%$, CR 21.2\%) than in patients without diabetes (5-year mortality: IR $22.2 \%$, CR $14.1 \%$ ). In a multivariable model that included the Mayo Clinic risk score, which was by far the most powerful independent predictor, IR and DM were also independent predictors (table 3). There was no significant evidence that the effect of CR was different between patients with and without diabetes.

By univariate analysis, the HR for repeat revascularisation with respect to IR in patients with diabetes was 1.10 (0.92 to $1.33) ; \mathrm{p}=0.28$, while it was $1.23(1.09$ to 1.38$) ; \mathrm{p}<0.001$ in patients without diabetes. In a multivariable model that included Mayo Clinic risk scores for death and death/MI as well as risk factors for restenosis, IR and DM were also independent predictors of repeat revascularisation (table 4). There was no significant evidence that the effect of CR was different between patients with and without diabetes. 
Table 1 Baseline clinical characteristics

\begin{tabular}{|c|c|c|c|c|c|c|c|c|c|}
\hline \multirow{2}{*}{$\begin{array}{l}\text { Variable } \\
\mathbf{n}(\%) \\
\text { Age, years }\end{array}$} & \multicolumn{2}{|c|}{$\begin{array}{l}\text { Diabetes IR } \\
(n=668)\end{array}$} & \multicolumn{2}{|c|}{$\begin{array}{l}\text { Diabetes CR } \\
(n=757)\end{array}$} & \multicolumn{2}{|c|}{$\begin{array}{l}\text { Non-diabetes IR } \\
(n=1709)\end{array}$} & \multicolumn{2}{|c|}{$\begin{array}{l}\text { Non-diabetes CR } \\
(n=2216)\end{array}$} & \multirow{2}{*}{$\frac{\text { p Value* }}{0.97}$} \\
\hline & 69.1 & (11.9) & 66.4 & $(11.5) \dagger$ & 69.6 & $(12.7)$ & 66.2 & $(12.1) \ddagger$ & \\
\hline Male gender & 441 & $(66 \%)$ & 499 & $(66 \%)$ & 1237 & $(72 \%)$ & 1564 & $(71 \%)$ & $<0.001$ \\
\hline Risk score for long-term death & 6.3 & $(2.6)$ & 5.3 & $(2.5) \ddagger$ & 5.0 & $(2.7)$ & 4.1 & $(2.5) \ddagger$ & $<0.001$ \\
\hline Risk score for long-term death/MI & 7.4 & (3.1) & 6.0 & $(2.8) \ddagger$ & 5.4 & (3.4) & 4.0 & $(3.1) \ddagger$ & $<0.001$ \\
\hline Hypertension & 552 & $(85 \%)$ & 631 & $(86 \%)$ & 1133 & $(70 \%)$ & 1438 & $(68 \%)$ & $<0.001$ \\
\hline \multicolumn{3}{|l|}{ Smoking status } & & & & & & & 0.003 \\
\hline Never & 237 & $(37 \%)$ & 271 & $(36 \%)$ & 607 & $(37 \%)$ & 732 & $(34 \%)$ & \\
\hline Former & 305 & $(47 \%)$ & 357 & $(48 \%)$ & 713 & $(43 \%)$ & 960 & $(44 \%)$ & \\
\hline Current & 102 & $(16 \%)$ & 117 & $(16 \%)$ & 343 & $(21 \%)$ & 477 & $(22 \%)$ & \\
\hline Hyperlipidaemia & 514 & $(83 \%)$ & 594 & $(83 \%)$ & 1119 & $(72 \%)$ & 1531 & $(76 \%) \ddagger$ & $<0.001$ \\
\hline Body mass index, $\mathrm{Kg} / \mathrm{m}^{2}$ & 31.6 & (6.9) & 32.0 & $(6.7)$ & 28.7 & $(5.5)$ & 29.0 & $(5.5)$ & $<0.001$ \\
\hline History of prior MI & 225 & $(34 \%)$ & 196 & $(26 \%)$ & 483 & $(29 \%)$ & 414 & $(19 \%) \ddagger$ & $<0.001$ \\
\hline Acute coronary syndrome, $\mathrm{n}$ & 378 & $(57 \%)$ & 402 & $(54 \%)$ & 1136 & $(67 \%)$ & 1376 & $(63 \%) \ddagger$ & $<0.001$ \\
\hline Canadian Heart Class III, IV & 317 & $(47 \%)$ & 376 & $(50 \%)$ & 790 & $(46 \%)$ & 1138 & $(51 \%)$ & 0.75 \\
\hline \multicolumn{3}{|l|}{ Predominant symptom } & & & & & & & $<0.001$ \\
\hline Chest pain & 524 & $(78 \%)$ & 581 & $(77 \%)$ & 1448 & $(85 \%)$ & 1842 & $(83 \%) \dagger$ & \\
\hline Other & 144 & $(22 \%)$ & 176 & $23 \%$ & 261 & $15 \%$ & 374 & $17 \%$ & \\
\hline \multicolumn{3}{|l|}{ History of CHF } & & & & & & & $<0.001$ \\
\hline Never & 439 & $(70 \%)$ & 596 & $(83 \%)$ & 1377 & $(84 \%)$ & 1928 & $(90 \%)$ & \\
\hline Ever & 192 & $(30 \%)$ & 125 & $(17 \%)$ & 263 & $(17 \%)$ & 205 & $(9 \%)$ & \\
\hline \multicolumn{3}{|l|}{ Most recent MI } & & & & & & & $<0.001$ \\
\hline$<24 \mathrm{~h}$ & 114 & $(17 \%)$ & 96 & $(13 \%) \ddagger$ & 447 & $(26 \%)$ & 471 & $(22 \%) \ddagger$ & \\
\hline $1-7$ days & 151 & $(23 \%)$ & 118 & $(16 \%)$ & 348 & $(21 \%)$ & 345 & $(16 \%)$ & \\
\hline$>7$ days & 162 & $(25 \%)$ & 165 & $(22 \%)$ & 332 & $(20 \%)$ & 316 & $(14 \%)$ & \\
\hline Never & 231 & $(35 \%)$ & 368 & $(49 \%)$ & 560 & $(33 \%)$ & 1054 & $(48 \%)$ & \\
\hline Prior $\mathrm{PCl}$ & 148 & $(22 \%)$ & 196 & $(26 \%)$ & 279 & $(16 \%)$ & 443 & $(20 \%) \ddagger$ & $<0.001$ \\
\hline Peripheral vascular disease & 116 & $(18 \%)$ & 123 & $(17 \%)$ & 168 & $(10 \%)$ & 157 & $(7 \%)$ & $<0.001$ \\
\hline Cerebrovascular disease & 115 & $(18 \%)$ & 97 & $(13 \%)$ & 201 & $(12 \%)$ & 186 & $(9 \%)$ & $<0.001$ \\
\hline Moderate/severe renal disease & 51 & $(8 \%)$ & 59 & $(8 \%)$ & 62 & $(4 \%)$ & 34 & $(2 \%)$ & $<0.001$ \\
\hline Chronic obstructive lung disease & 101 & $(15 \%)$ & 89 & $(12 \%)$ & 189 & $(11 \%)$ & 237 & $(11 \%)$ & 0.012 \\
\hline Peptic ulcer disease & 39 & $(6 \%)$ & 29 & $(4 \%)$ & 91 & $(5 \%)$ & 120 & $(6 \%) \ddagger$ & 0.37 \\
\hline Tumour/lymphoma/leukaemia & 103 & $(16 \%)$ & 88 & $(12 \%)$ & 244 & $(14 \%)$ & 265 & $(12 \%)$ & 0.69 \\
\hline Metastatic cancer & 5 & $(1 \%)$ & 5 & $(1 \%)$ & 14 & $(1 \%)$ & 15 & $(1 \%)$ & 0.89 \\
\hline Prophylactic IABP & 18 & $(3 \%)$ & 1 & $(0 \%)$ & 29 & $(2 \%)$ & 19 & $(1 \%)$ & 0.75 \\
\hline LVEF, n (\%) & & & & & & & & & $<0.001$ \\
\hline$>40 \%$ & 260 & $(39 \%)$ & 386 & $(51 \%)$ & 773 & $(45 \%)$ & 1167 & $(53 \%)$ & \\
\hline$\leq 40 \%$ & 130 & $(19 \%)$ & 86 & $(11 \%)$ & 242 & $(14 \%)$ & 146 & $(7 \%)$ & \\
\hline Not available & 278 & $(42 \%)$ & 285 & $(38 \%)$ & 694 & $(41 \%)$ & 903 & $(41 \%)$ & \\
\hline
\end{tabular}

\section{DISCUSSION}

The main findings of our study are the following. First, we observed that IR is common (47\%) following PCI in our population of patients with diabetes with multivessel coronary artery disease without prior CABG, and is marginally more frequent than in patients without diabetes $(43 \%)$. Second, CR is associated with lower long-term mortality in patients with diabetes and patients without diabetes. The lower relative risk with CR versus IR was similar in both groups (41\% vs 36\%), however, the absolute risk was significantly higher in patients with diabetes $(14.6 \%$ at 5 years) compared with patients without diabetes $(8.1 \%)$. Third, this effect was present in the BMS and DES eras. Finally, the relationship between CR and mortality was present regardless of whether revascularisation was for stable disease or ACS.
Prior studies have reported a variable frequency (41-67\%) and prognostic impact of IR following PCI. There are many reasons for these inconsistencies. First, there is no uniformly accepted definition of IR, and it has been generally limited to angiographic criteria. ${ }^{3} 512$ The commonly used anatomical definitions have used the presence of an untreated $\geq 50 \%$ stenosis in any coronary artery that is $>1.5 \mathrm{~mm}$ in diameter, but others have been more stringent with $>70 \%$ stenosis as the cut-off, and some limiting assessment to vessels $>2.5 \mathrm{~mm}$ in diameter. ${ }^{12}$ However, there is a need for a practical, simple, intuitive definition of IR for clinical studies and practice. The pragmatic definition of IR used in the present study avoids the need to integrate vessel diameter, a measure that is generally neither recorded in large databases nor routinely measured in practice. Rather, we focused on the proximal coronary segments of the three major 
Table 2 Angiographic and procedural characteristics

\begin{tabular}{|c|c|c|c|c|c|c|c|c|c|}
\hline \multirow{2}{*}{$\begin{array}{l}\text { Variable } \mathbf{n}(\%) \\
\geq 70 \% \text { Stenosis proximal or mid-left anterior descending artery }\end{array}$} & \multicolumn{2}{|c|}{$\begin{array}{l}\text { Diabetes IR } \\
(n=668)\end{array}$} & \multicolumn{2}{|c|}{$\begin{array}{l}\text { Diabetes CR } \\
(n=757)\end{array}$} & \multicolumn{2}{|c|}{$\begin{array}{l}\text { Non-diabetes } \\
\text { IR }(n=1709)\end{array}$} & \multicolumn{2}{|c|}{$\begin{array}{l}\text { Non-diabetes CR } \\
(n=2216)\end{array}$} & \multirow{2}{*}{$\frac{\text { p Value* }}{0.026}$} \\
\hline & 518 & $(78 \%)$ & 434 & $(57 \%) \dagger$ & 1313 & $(77 \%)$ & 1180 & $(53 \%) \dagger$ & \\
\hline$\geq 70 \%$ Stenosis proximal or distal circumflex artery & 246 & $(37 \%)$ & 125 & $(17 \%) \dagger$ & 565 & $(33 \%)$ & 421 & $(19 \%) \dagger$ & 0.50 \\
\hline$\geq 70 \%$ Stenosis right coronary artery & 586 & $(88 \%)$ & 430 & $(57 \%) \dagger$ & 1491 & $(87 \%)$ & 1283 & $(58 \%) \dagger$ & 0.66 \\
\hline$\geq 70 \%$ Stenosis left main artery & 18 & $(3 \%)$ & 13 & $(2 \%)$ & 49 & $(3 \%)$ & 22 & $(1 \%) \dagger$ & 0.39 \\
\hline Worst lesion type & & & & & & & & & 0.31 \\
\hline A & 8 & $(1 \%)$ & 13 & $(2 \%)$ & 21 & $(1 \%)$ & 42 & $(2 \%) \dagger$ & \\
\hline B1 & 83 & $(14 \%)$ & 103 & $(14 \%)$ & 198 & $(14 \%)$ & 304 & $(15 \%)$ & \\
\hline B2 & 181 & $(31 \%)$ & 268 & $(37 \%)$ & 467 & $(33 \%)$ & 799 & $(39 \%)$ & \\
\hline C & 303 & $(53 \%)$ & 339 & $(47 \%)$ & 736 & $(52 \%)$ & 925 & $(45 \%)$ & \\
\hline Chronic total occlusion treated & 25 & $(4 \%)$ & 28 & $(4 \%)$ & 68 & $(4 \%)$ & 93 & $(4 \%)$ & 0.53 \\
\hline Thrombus in any lesion & 146 & $(25 \%)$ & 158 & $(22 \%)$ & 480 & $(33 \%)$ & 642 & $(30 \%)$ & $<0.001$ \\
\hline Calcium in any stenosis & 295 & $(54 \%)$ & 325 & $(48 \%) \ddagger$ & 732 & $(53 \%)$ & 821 & $(42 \%) \dagger$ & 0.018 \\
\hline Preprocedure TIMI flow 0/1 in any vessel & 84 & $(18 \%)$ & 98 & $(17 \%)$ & 293 & $(25 \%)$ & 356 & $(22 \%) \ddagger$ & $<0.001$ \\
\hline Urgency of $\mathrm{PCl}$ & & & & & & & & & $<0.001$ \\
\hline Elective & 238 & $(36 \%)$ & 319 & $(42 \%) \dagger$ & 512 & $(30 \%)$ & 764 & $(34 \%) \dagger$ & \\
\hline Non-elective & 429 & $(64 \%)$ & 438 & $(58 \%)$ & 1197 & $(70 \%)$ & 1451 & $(66 \%)$ & \\
\hline Number of vessels treated & & & & & & & & & 0.62 \\
\hline 1 & 529 & $(79 \%)$ & 499 & $(66 \%)$ & 1352 & $(79 \%)$ & 1498 & $(68 \%)$ & \\
\hline 2 & 78 & $(12 \%)$ & 241 & $(32 \%)$ & 194 & $(11 \%)$ & 676 & $(31 \%)$ & \\
\hline 3 & 9 & $(1 \%)$ & 16 & $(2 \%)$ & 19 & $(1 \%)$ & 39 & $(2 \%)$ & \\
\hline Branch vessel $\mathrm{PCl}$ only & 51 & $(8 \%)$ & 0 & $(0 \%) \dagger$ & 144 & $(8 \%)$ & 0 & $(0 \%) \dagger$ & \\
\hline Total number of stents placed & 1.8 & $(1.1)$ & 2.0 & $(1.1) \dagger$ & 1.7 & $(1.0)$ & 1.9 & $(1.1) \dagger$ & 0.009 \\
\hline Use of drug-eluting stents & 265 & $(43 \%)$ & 366 & $(48 \%) \ddagger$ & 573 & $(37 \%)$ & 882 & $(40 \%) \ddagger$ & $<0.001$ \\
\hline $\mathrm{PCI}$ to left anterior descending artery & 374 & $(56 \%)$ & 450 & $(59 \%)$ & 851 & $(50 \%)$ & 1221 & $(55 \%) \dagger$ & 0.001 \\
\hline $\mathrm{PCl}$ to left main artery & 19 & $(3 \%)$ & 17 & $(2 \%)$ & 34 & $(2 \%)$ & 32 & $(1 \%)$ & 0.046 \\
\hline Postprocedure TIMI 3 flow in all vessels & 585 & $(97 \%)$ & 725 & $(98 \%)$ & 1448 & $(95 \%)$ & 2122 & $(98 \%) \dagger$ & 0.44 \\
\hline Maximum device size (mm) & 3.27 & $(0.5)$ & 3.35 & $(0.5) \ddagger$ & 3.35 & $(0.5)$ & 3.41 & $(0.6) \dagger$ & $<0.001$ \\
\hline \multicolumn{10}{|l|}{ Inhospital outcomes } \\
\hline Inhospital any MI, n (\%) & 37 & $(6 \%)$ & 36 & $(5 \%)$ & 72 & $(4 \%)$ & 96 & $(4 \%)$ & 0.19 \\
\hline Inhospital target lesion redilation & 3 & $(0 \%)$ & 2 & $(0 \%)$ & 5 & $(0 \%)$ & 10 & $(0 \%)$ & 0.87 \\
\hline
\end{tabular}

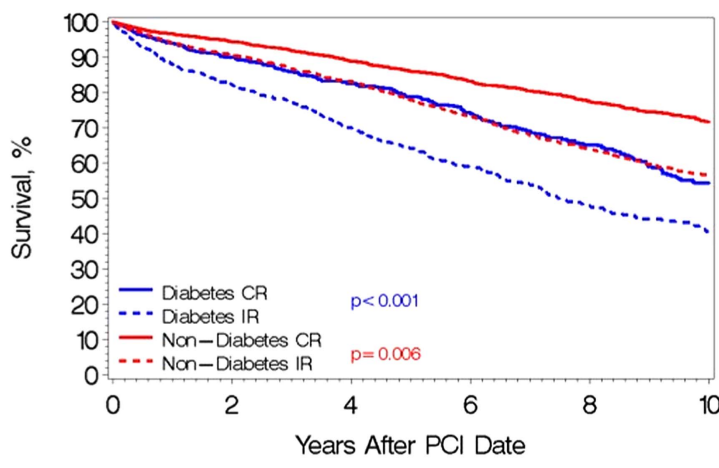

$\begin{array}{lllllll}\text { Diabetes CR } & 757 & 584 & 450 & 324 & 223 & 122 \\ \text { Diabetes IR } & 668 & 468 & 346 & 247 & 145 & 73 \\ \text { Non-Diabetes CR } & 2216 & 1809 & 1510 & 1175 & 856 & 568 \\ \text { Non-Diabetes IR } & 1709 & 1382 & 1122 & 809 & 556 & 349\end{array}$

Figure 1 Unadjusted mortality curves during follow-up for patients with diabetes and patients without diabetes according to complete (CR) or incomplete revascularisation (IR). PCl, percutaneous coronary intervention.

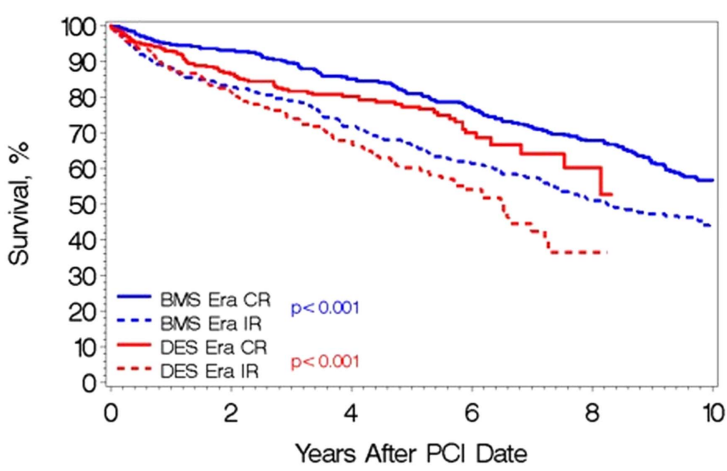

$\begin{array}{lllllll}\text { BMS Era CR } & 367 & 327 & 295 & 262 & 210 & 122 \\ \text { BMS Era IR } & 334 & 267 & 229 & 103 & 137 & 73 \\ \text { DES Era CR } & 390 & 257 & 155 & 62 & 13 & 0 \\ \text { DES Era IR } & 334 & 201 & 117 & 54 & 8 & 0\end{array}$

Figure 2 Unadjusted mortality curves during follow-up for bare-metal stent (BMS) and drug-eluting stent (DES) eras. CR, complete revascularisation; IR, incomplete revascularisation; $\mathrm{PCl}$, percutaneous coronary intervention. 


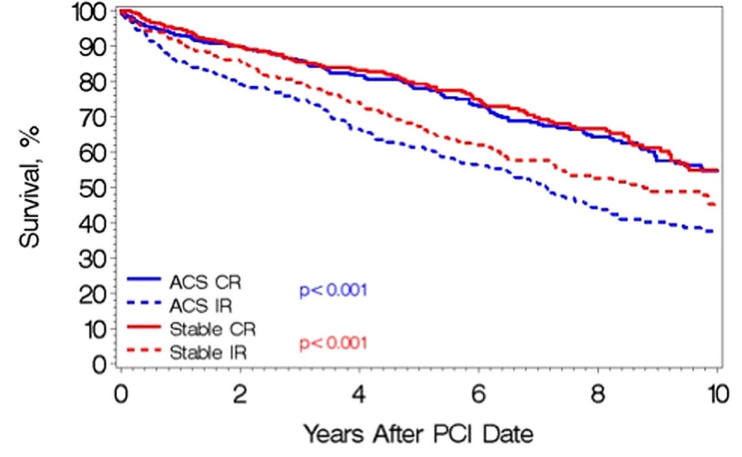

$\begin{array}{lllllll}\text { ACS CR } & 402 & 312 & 239 & 173 & 123 & 67 \\ \text { ACS IR } & 378 & 259 & 185 & 133 & 76 & 40 \\ \text { Stable CR } & 349 & 267 & 207 & 147 & 99 & 55 \\ \text { Stable IR } & 282 & 204 & 156 & 110 & 67 & 32\end{array}$

Figure 3 Unadjusted mortality curves during follow-up for stable disease versus acute coronary syndrome (ACS). CR, complete revascularisation; IR, incomplete revascularisation; $\mathrm{PCl}$, percutaneous coronary intervention.

epicardial arteries as surrogates for large areas of myocardium at jeopardy from significant (>70\% diameter stenosis) atherosclerotic lesions, and hence ischaemic burden.

Our study is unique in that it provides very long-term follow-up among a large 'all-comers' cohort of patients with diabetes who were evaluated to address the impact of the completeness of percutaneous revascularisation. It demonstrates that non-diabetic status and CR are independently associated with a lower risk of death. This risk is independent of the many adverse baseline characteristics that cluster in patients with diabetes and known to influence survival (table 3 ). While the relative impact of CR was similar in patients with diabetes and patients without diabetes, CR resulted in a significantly greater absolute risk reduction in patients with diabetes. Thus, survival of patients without diabetes with IR was identical to that of patients with diabetes with CR (figure 1). The improved outcomes associated with CR were present in the BMS and DES eras suggesting that changes in stent technology and adjunctive pharmacological therapies have not significantly altered this relationship. Moreover, the association hold true regardless of the acuity of presentation at the time of PCI, a fact that to the best of our knowledge has not been previously reported. Our data is consistent with that published by Schwartz et al, ${ }^{7}$ Garcia et al ${ }^{13}$ and Head et $a l^{14}$ from post hoc analyses of clinical trials who described the impact of completeness of revascularisation on long-term (5 years) cardiovascular outcomes. To date, the only

Table 3 Multivariable Cox model for long-term mortality

\begin{tabular}{lccccc}
\hline & \multicolumn{5}{c}{$\begin{array}{l}95 \% \text { HR } \\
\text { confidence }\end{array}$} \\
Variable & $\chi^{2}$ test & HR & limits & p Value \\
\hline Mayo long-term mortality risk score & 1257 & 1.41 & 1.38 & 1.43 & $<0.001$ \\
IR & 22.5 & & & & $<0.001$ \\
Diabetes & 13.1 & & & & 0.008 \\
Interaction (CR×diabetes) & 0.7 & & & & 0.39 \\
IR effect in patients with diabetes & & 1.23 & 1.04 & 1.46 & 0.018 \\
IR effect in patients without diabetes & & 1.35 & 1.19 & 1.52 & $<0.001$ \\
Diabetes effect in IR & & 1.21 & 1.05 & 1.40 & 0.008 \\
Diabetes effect in CR & & 1.33 & 1.14 & 1.55 & $<0.001$ \\
\hline CR, complete revascularisation; IR, incomplete revascularisation.
\end{tabular}

Jiménez-Navarro MF, et al. Heart 2015;101:1233-1239. doi:10.1136/heartjnl-2014-307143
Table 4 Multivariable Cox model for long-term repeat revascularisation

\begin{tabular}{|c|c|c|c|c|c|}
\hline \multirow{2}{*}{$\begin{array}{l}\text { Variable } \\
\text { Age (per decade) }\end{array}$} & \multirow{2}{*}{$\begin{array}{l}\chi^{2} \text { test } \\
29.4\end{array}$} & \multirow{2}{*}{$\begin{array}{l}\text { HR } \\
0.86\end{array}$} & \multicolumn{2}{|c|}{$\begin{array}{l}95 \% \text { HR } \\
\text { confidence } \\
\text { limits }\end{array}$} & \multirow{2}{*}{$\begin{array}{l}\text { p Value } \\
<0.001\end{array}$} \\
\hline & & & 0.81 & 0.91 & \\
\hline Device size (mm) & 14.1 & 0.82 & 0.74 & 0.91 & $<0.001$ \\
\hline Peripheral vascular disease & 10.6 & 1.33 & 1.12 & 1.57 & 0.001 \\
\hline Mayo long-term mortality risk score & 8.4 & 0.96 & 0.94 & 0.99 & 0.004 \\
\hline Drug-eluting stent use & 6.9 & 0.86 & 0.77 & 0.96 & 0.008 \\
\hline CVA/TIA & 4.6 & 1.20 & 1.02 & 1.41 & 0.032 \\
\hline Current smoker & 1.3 & 0.93 & 0.81 & 1.06 & 0.25 \\
\hline History of MI & 1.1 & 0.94 & 0.84 & 1.06 & 0.29 \\
\hline Male & 1.0 & 0.95 & 0.85 & 1.06 & 0.32 \\
\hline Calcium in stenosis & 0.36 & 1.03 & 0.93 & 1.14 & 0.55 \\
\hline IR & 18.4 & & & & $<0.001$ \\
\hline Diabetes & 12.2 & & & & $<0.001$ \\
\hline Interaction (IR×Diabetes) & 0.6 & & & & 0.43 \\
\hline IR effect in patients with diabetes & & 1.18 & 0.98 & 1.43 & 0.078 \\
\hline IR effect in patients without diabetes & & 1.29 & 1.15 & 1.45 & $<0.001$ \\
\hline Diabetes effect in IR & & 1.20 & 1.02 & 1.42 & 0.001 \\
\hline Diabetes effect in CR & & 1.31 & 1.13 & 1.53 & 0.029 \\
\hline
\end{tabular}

published observational 'all-comers' study reporting on patients with diabetes has a small $(n=191)$ sample size ${ }^{15}$ in which CR was associated with better composite outcomes, but it was underpowered to show a statistically significant relationship with hard end points such as death.

Patients with diabetes represent a large proportion of patients requiring consideration for revasularisation. ${ }^{2}$ The FREEDOM trial $^{16}$ and substudies from the SYNTAX trials ${ }^{17}$ have confirmed the superiority of CABG over PCI for patients with diabetes with advanced multivessel disease. Therefore the present guidelinesbased approach in patients with diabetes with multivessel disease is the calculation of the SYNTAX score and a review by the "heart team'. CABG is a class 1 indication in patients with three vessel and/or left main disease and a SYNTAX score of $>22 .{ }^{18} 19$ However, PCI remains a consideration for a significant proportion of patients with diabetes either because they are not suitable for CABG (eg, diffuse distal vessels, comorbidities) or because the patient does not wish to have surgery. ${ }^{4} 20$ Thus, our findings remain pertinent to contemporary practice and the significance of CR merits further investigation.

Intuitively, the rate of single vessel PCI would have been expected to be low in those with CR. However, despite, the presence of multivessel disease, the majority $(72 \%)$ of patients in our study underwent single vessel PCI, regardless of the diabetes status. Among those achieving CR, the frequency of single vessel PCI was marginally lower at $66-68 \%$. This compares with single vessel PCI rates of $85 \%$ and multivessel disease frequency of approximately $50 \%$ in our practice, figures that have remained unchanged over a 25 -year period. $^{21}$ Thus, the high frequency of single vessel PCI reflects the overall practice of PCI and also the inclusion criterion which limited the segments of interest to the proximal coronary tree.

The present study has several limitations. First, we did not perform systematic assessment of ischaemic burden (eg, fractional flow reserve measurement or stress testing) or viability to ascertain the full clinical significance of the stenoses. However, 
we believe that the cohort selected for the study would have included patients with clinically meaningful and significant lesions. Moreover, perfusion scintigraphy and other stress tests are not without their own limitations in multivessel coronary disease. ${ }^{22} 23$ Second, our study is retrospective and subject to the limitations of such analyses. Thus, we did not prospectively collect the reasons for CR versus IR, nor the reason for unsuccessful PCI among those excluded from the study. This raises the possibility of unmeasured confounders; for example, the success or ease of the PCI procedure may itself be associated with the decision to proceed with CR versus IR and may be associated with the likelihood of adverse events. Patients with IR had more advanced disease, which may have contributed to the relationship with adverse outcomes. However, we performed multivariate analysis including a large number of variables to adjust for these differences between the groups.

In conclusion, our all-comers study, among the largest cohort of patients with diabetes undergoing percutaneous coronary revascularisation, confirms the adverse prognostic association of IR and long-term mortality. While our retrospective study cannot establish a causal link, it is hypothesis generating and highlights the potentially important clinical significance of achieving CR and assessing the optimal strategy for patients with diabetes with multivessel coronary disease. This needs to be considered in the context of other variables ${ }^{24-27}$ such as age, LV function, severity of symptoms, myocardial viability, ${ }^{28}$ antiplatelet therapy ${ }^{29}$ and coronary anatomy (presence of chronic total occlusion, suitability of the left anterior descending artery for grafting and quality of the distal vessels).

\section{Key messages}

\section{What is already known on this subject?}

It is well known that patients with diabetes have a worse prognosis than patients without diabetes after percutaneous coronary revascularisation. Moreover, there is debate about impact of complete revascularisation among patients with diabetes and patients without diabetes with multivessel disease. In this study, we assess the impact of complete revascularisation, using a relatively simple anatomical definition, in a large (>5000 patients) cohort, on long-term outcomes (median follow-up 8 years).

\section{What might this study add?}

Complete revascularisation is associated with lower long-term mortality in patients with diabetes and patients without diabetes. However absolute risk reduction was significantly higher in patients with diabetes compared with patients without diabetes. This was present in patients with stable disease and acute coronary syndromes.

\section{How might this impact on clinical practice?}

The study is significant because it highlights the potential importance of complete revascularisation in patients with diabetes as well as patients without diabetes across the spectrum of coronary artery disease presentations.

Contributors All authors have substantial contributions to this paper.

Funding MFJ-N received a grant from Institute of Health Carlos III, ISCIII (Ministry of Economy and Competitiveness) (Spain) (Beca BAE) and from Sociedad Andaluza de Cardiología (Beca Estancia Extranjero).
Competing interests None.

Patient consent Obtained.

Ethics approval The Institutional Review Board at Mayo Clinic.

Provenance and peer review Not commissioned; externally peer reviewed.

Data sharing statement Limited.

\section{REFERENCES}

1 Roger VL, Go AS, Lloyd-Jones DM, et al. Executive summary: heart disease and stroke statistics - 2012 update: a report from the American Heart Association. Circulation 2012;125:188-97.

2 Bates ER. Multivessel coronary artery disease revascularisation strategies in patients with diabetes mellitus. Heart 2013;99:1633-5.

3 Gossl M, Faxon DP, Bell MR, et al. Complete versus incomplete revascularization with coronary artery bypass graft or percutaneous intervention in stable coronary artery disease. Circ Cardiovasc Interv 2012;5:597-604

4 Rosner GF, Kirtane AJ, Genereux P, et al. Impact of the presence and extent of incomplete angiographic revascularization after percutaneous coronary intervention in acute coronary syndromes: the Acute Catheterization and Urgent Intervention Triage Strategy (ACUITY) trial. Circulation 2012;125:2613-20.

$5 \mathrm{Kim}$ YH, Park DW, Lee JY, et al. Impact of angiographic complete revascularization after drug-eluting stent implantation or coronary artery bypass graft surgery for multivessel coronary artery disease. Circulation 2011;123:2373-81.

6 van den Brand MJ, Rensing BJ, Morel MA, et al. The effect of completeness of revascularization on event-free survival at one year in the ARTS trial. J Am Coll Cardiol 2002;39:559-64.

7 Schwartz L, Bertolet M, Feit F, et al. Impact of completeness of revascularization on long-term cardiovascular outcomes in patients with type 2 diabetes mellitus: results from the Bypass Angioplasty Revascularization Investigation 2 Diabetes (BARI 2D). Circ Cardiovasc Interv 2012;5:166-73.

8 Hannan EL, Wu C, Walford G, et al. Incomplete revascularization in the era of drug-eluting stents: impact on adverse outcomes. JACC Cardiovasc Interv 2009:2:17-25.

9 Hannan EL, Racz M, Holmes DR, et al. Impact of completeness of percutaneous coronary intervention revascularization on long-term outcomes in the stent era. Circulation 2006;113:2406-12.

10 Alderman EL, Stadius M. The angiographic definitions of the Bypass Angioplasty Revascularization Investigation study (BARI). Coron Artery Dis 1992:3:1189-207.

11 Singh M, Holmes DR, Lennon RJ, et al. Development and validation of risk adjustment models for long-term mortality and myocardial infarction following percutaneous coronary interventions. Circ Cardiovasc Interv 2010;3:423-30.

12 Shanon J, Colombo A. Revascularization in multivessel CAD: a functional approach. Nat Rev Cardiol 2012;9:243-52.

13 Garcia S, Sandoval Y, Roukoz H, et al. Outcomes after complete versus incomplete revascularization of patients with multivessel coronary artery disease: a meta-analysis of 89,883 patients enrolled in randomized clinical trials and observational studies. J Am Coll Cardiol 2013;62:1421-31.

14 Head SJ, Mack MJ, Holmes DR Jr, et al. Incidence, predictors and outcomes of incomplete revascularization after percutaneous coronary intervention and coronary artery bypass grafting: a subgroup analysis of 3-year SYNTAX data. Eur J Cardiothorac Surg 2012:41:535-41.

15 Chung JW, Park KH, Lee MH, et al. Benefit of complete revascularization in patients with multivessel coronary disease in the drug-eluting stent era. Circ J 2012:76:1624-30.

16 Farkouh ME, Domanski M, Sleeper LA, et al. Strategies for multivessel revascularization in patients with diabetes. N Engl J Med 2012;367:2375-84.

17 Farooq V, Head SJ, Kappetein AP, et al. Widening clinical aplication of the Syntax Score. Heart 2014:100:276-87.

18 Windecker S, Kolh P, Alfonso F, et al. ESC/EACTS Guidelines on myocardial revascularization: The Task Force on Myocardial Revascularization of the European Society of Cardiology (ESC) and the European Association for Cardio-Thoracic Surgery (EACTS) Developed with the special contribution of the European Association of Percutaneous Cardiovascular Interventions (EAPCI). Eur Heart J 2014;35:2541-619.

19 Sianos G, Morel MA, Kappetein AP, et al. The SYNTAX Score: an angiographic tool grading the complexity of coronary artery disease. Eurolntervention 2005;1:219-27.

20 Hochman JS, Lamas GA, Buller CE, et al, Occluded Artery Trial Investigators. Coronary intervention for persistent occlusion after myocardial infarction. $N$ Eng/ J Med 2006:355:2395-407

21 Singh M, Rihal CS, Gersh BJ, et al. Twenty-five-year experience in in-hospital and long-term outcome after percutaneous coronary intervention: a single-institution experience. Circulation 2007:115:2835-41.

22 Lima RS, Watson DD, Goode AR, et al. Incremental value of combined perfusion and function over perfusion alone by gated SPECT myocardial perfusion imaging for 
detection of severe three-vessel coronary artery disease. J Am Coll Cardiol 2003:42:64-70.

23 Lin GA, Dudley RA, Lucas FL, et al. Frequency of stress testing to document ischemia prior to elective percutaneous coronary intervention. JAMA 2008;300:1765-73.

24 Prasad A, Stone GW, Stuckey TD, et al. Impact of diabetes mellitus on myocardial perfusion after primary angioplasty in patients with acute myocardial infarction. J Am Coll Cardiol 2005:45:508-14.

25 Cassar A, Chareonthaitawee P, Rihal CS, et al. Lack of correlation between noninvasive stress tests and invasive coronary vasomotor dysfunction in patients with nonobstructive coronary artery disease. Circ Cardiovasc Interv 2009;2:237-44.
26 Jiménez-Quevedo P, Suzuki N, Corros C, et al. Assessment of dynamic coronary plaque changes and the clinical consequences in type-II diabetic patients: a serial intracoronary ultrasound study. Rev Esp Cardiol 2011;64:557-63.

27 Muñoz-Garach A, Mancha-Doblas I, Fernández-García JC. Control de la diabetes en pacientes coronarios: ¿Hasta qué objetivo y con qué fármacos? ¿Cuándo es necesaria la evaluación cardiológica? Cardiocore 2015;50:38-42.

28 Rydén L, Grant PJ, Anker SD, et al. ESC guidelines on diabetes, pre-diabetes, and cardiovascular diseases developed in collaboration with the EASD—summary. Eur Heart J 2013;34:3035-87.

29 Pilgrim T, Windecker S. Coronary artery disease review series: antiplatelet therapy for secondary prevention of coronary artery disease. Heart 2014;100:1750-6. 